\title{
Adverse Drug Reactions in Selected Wards of the Yangon General Hospital and Yangon Specialty Hospital During the First Quarter of 2019: An Active Pharmacovigilance Study in Myanmar
}

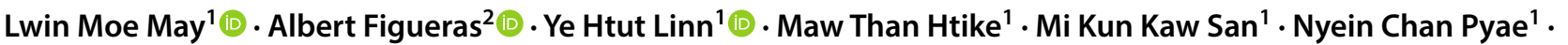 \\ Khin Hnin Aye ${ }^{1}$ - Ei Ei Aung ${ }^{1}$ - Nilar Win ${ }^{1}$. Wine Thawda ${ }^{1}$. Zin Wah Linn ${ }^{1}$ - Yin Min Kyaw ${ }^{1}$ - Ya Min ${ }^{1}$ - Zaw Win Than ${ }^{1}$. \\ Moe Pan Khaing ${ }^{1} \cdot$ Thurein Win $^{1} \cdot$ Pyi Phyo Htet ${ }^{1} \cdot$ Nu Nu Aye $^{1}$
}

Published online: 10 February 2020

(c) The Author(s) 2020

\begin{abstract}
Background Previous studies in Europe and the USA have reported a high prevalence of adverse drug reactions (ADRs), but data on local ADRs in Myanmar are sparse.

Objective Our objective was to study ADRs in patients admitted to selected wards of Yangon General Hospital (YGH) and Yangon Specialty Hospital (YSH), Myanmar.

Methods This was a prospective observational study in three hospital wards during the first quarter of 2019. Suspected ADRs were carefully investigated in a face-to-face interview with each patient and via review of clinical records. Patients transferred to other wards or discharged were followed-up by the researchers until day 28 after admission. ADRs were divided into those that (1) led to the admission and (2) occurred during the hospital stay or after discharge (up to day 28 after admission). Results A total of 65 ADRs were identified, with 47 (29.4\%) of 160 patients experiencing at least one ADR. Among these, $16(24.6 \%)$ had led to hospital admission and $49(75.4 \%)$ occurred in 31 patients during their hospital stay. Of 160 patients, 21 had taken at least one herbal remedy and six of these developed an ADR. Five ADR-drug associations (hypokalaemia with methylprednisolone, increased transaminase levels with standard antituberculosis drugs, upper gastrointestinal bleeding with nonsteroidal anti-inflammatory drugs, constipation with tramadol, and increased transaminase levels with herbal remedies) represented 18 (27.7\%) of the 65 ADRs in this study. According to the Schumock and Thornton preventability scale, more than half of these ADRs (35 [53.9\%]) were preventable.

Conclusion The present study highlights the existence of ADRs among patients attending these hospitals. The implementation of active pharmacovigilance in hospitals could be a helpful first step to improving the awareness of unwanted effects of medicines and patient safety, as well as a way to strengthen the national pharmacovigilance system in countries such as Myanmar.
\end{abstract}

\section{Introduction}

Multiple studies have emphasised the high prevalence and potential seriousness of adverse drug reactions (ADRs),

Electronic supplementary material The online version of this article (https://doi.org/10.1007/s40801-020-00180-0) contains supplementary material, which is available to authorized users.

Lwin Moe May

lwinmoemay@gmail.com

1 Department of Pharmacology, University of Medicine 1, Yangon, No. 245, Myoma-Kyaung Street, Lanmadaw Township, Yangon 11131, Myanmar

2 Fundació Institut Català de Farmacologia, Department of Pharmacology, Therapeutics and Toxicology, Universitat Autònoma de Barcelona, Barcelona, Spain especially among aged patients and those receiving polypharmacy. ADRs are especially relevant in hospitalised patients, with one meta-analysis reporting an estimated $6.7 \%$ of hospitalised patients in the USA developing a serious unwanted effect and a fatality rate of $0.32 \%$ [1]. In the USA, an estimated 2,216,000 serious ADRs occurred in hospitalised patients and caused over 106,000 deaths in 1994 [1]. According to a European Commission report, 3-10\% of hospital admissions between 2012 and 2014 were caused by ADRs, totalling about 2.5-8.4 million annually, 


\section{Key Points}

This initial study to determine the prevalence of adverse drug reactions (ADRs) in two hospitals in Myanmar found that almost one-third of the participating hospitalised patients presented with an unwanted effect.

One-quarter of the observed ADRs were associated with only three ADR-medicine combinations. Additionally, more than one-half of the identified ADRs in the study sample were considered preventable effects. Thus, increased awareness of pharmacovigilance could avoid many such cases and increase patient safety.

Six patients presented an ADR attributed to herbal remedies. Pharmacovigilance in settings with a high use of such traditional remedies should include clear guidance on their potential toxicity.

and $2.1-6.5 \%$ of hospitalised patients experienced an ADR, corresponding to $1.8-5.5$ million annually [2].

On the other hand, most emergency hospitalisations for recognised ADRs in older adults resulted from a few commonly used medications [3], suggesting that understanding of pharmacovigilance, awareness of potential ADRs, and identification of patients at risk could help prevent many of these situations, which prompt emergency admissions or complicate the clinical course of already hospitalised patients.

In 1968, the World Health Organization (WHO) established its Programme for International Drug Monitoring in response to the thalidomide disaster [4]; 136 countries are now full members and 29 are associate members of this programme. In 2018, Myanmar became an associate member [5]. Thus, the pharmacovigilance programme in Myanmar is at a very preliminary stage, although Myanmar's ADR reporting system was established in 2002 and the Myanmar Food and Drug Administration (FDA) has distributed an ADR reporting form to central, state, and regional hospitals; health offices; and drug advisory committee members. An implementation research report by postgraduate students and specialist clinicians from eight teaching hospitals under University of Medicine 1, Yangon, found that 44.9\% of respondents had poor awareness of the ADR reporting system and that several barriers to ADR reporting existed [6]. Another study conducted in eight teaching hospitals in Yangon showed that most assistant surgeons were not aware of the ADR reporting system (79.3\%), the ADR reporting form $(89.7 \%)$, or the department to which ADRs should be reported (83.3\%) [7].

A prospective observational study conducted for antimycobacterial drugs in a tuberculosis campaign in Myanmar found that 115 of 128 patients (88.3\%) experienced ADRs, and a total of 349 adverse effects were reported in 6 months [8].

To initiate a drug safety strategy for Myanmar, the first step is to provide evidence that ADRs are frequent in the country and to raise awareness among health professionals and drug authorities about the frequent complications of medical treatment. Therefore, the present study aimed to describe ADRs leading to hospital admission or occurring in patients admitted to selected wards of Yangon General Hospital (YGH) and Yangon Specialty Hospital (YSH).

\section{Methods}

A prospective observational study was designed and conducted in one medical and one surgical ward in YGH and one rheumatology ward in YSH between 1st January and 31st March 2019. YGH is a 1500-bed hospital and one of the biggest teaching hospitals in Myanmar, and YSH is a 500-bed hospital; both hospitals admit adult patients (aged $>12$ years according to the country's clinical classification). All patients admitted to the wards under study in YGH and YSH during the study period were identified during the first $24 \mathrm{~h}$ after admission to be followed-up until hospital discharge or day 28 after admission.

Exclusion criteria were any patients who took an overdose (deliberately or not), were critically ill (unstable vital signs, tracheotomy, or mechanical ventilation), were unable to understand and answer questions (i.e., could not speak Myanmar), or refused to participate or withdrew from the study.

Researchers were trained in how to identify ADRs, complete the reporting form (see the online Appendix), and review patients' treatment charts and laboratory test results, and were given resources describing common ADRs. Researchers were also trained in how to use the assessment tools adopted for the present study. A workshop was conducted to ensure researchers used diagnostic criteria and applied the algorithms consistently.

Potential study participants were given a full explanation of objectives, procedures, benefits, and possible risks of the study. Patients who were willing to participate in the study provided written informed consent; one patient refused to participate (Fig. 1).

All included patients attended a face-to-face interview during which they were asked about suspected ADRs, and researchers reviewed patients' clinical charts and laboratory test results. Researchers (14 clinical pharmacologists from the University of Medicine 1, Yangon) visited the study ward daily to identify any suspected ADRs in the recruited patients during a 4 -week period (28 days). All clinical staff were officially informed that a study on ADRs was 
taking place. If patients were transferred to another ward, the researchers followed them and continued observations for ADRs. If the patient was discharged from hospital, the researcher phoned them daily until the end of the follow-up period (day 28 after admission) to check for the occurrence of any ADR.

An ADR was defined according to the classical WHO definition ("Any response to a drug which is noxious, unintended and which occurs at doses normally used in man for prophylaxis, diagnosis, or therapy of disease, or for the modification of physiological function") [4]. All identified suspected ADRs were discussed by the study team of clinicians and pharmacologists weekly. The British National Formulary and specific bibliographic websites were used to assess previous knowledge about the identified ADRs. Each suspected ADR was classified according to the WHOAdverse Reactions Terminology (ART) dictionary. Causality was assessed using the Naranjo algorithm [9]. The severity of the ADR was also categorised according to the Hartwig severity scale [10], and preventability was assessed using the Schumock and Thornton preventability scale [11]. Polypharmacy was defined as more than five drugs being taken concomitantly by a single patient, and 'increased transaminase' was used when the transaminase level was at least 1.5 times higher than the upper normal reference value given by the hospital laboratory.

\subsection{Data Analysis}

Continuous variables were presented as means \pm standard deviations, and categorical variables were presented as number and percentage. The variables were compared between patients with ADRs and those without ADRs using descriptive statistical tests, the independent samples $t$ test for continuous variables, and the Chi-squared test for categorical variables. Binary logistic regression (univariate and multivariate analysis using a forward conditional method) was performed to examine possible associations between ADR occurrence and different variables. Possible confounders were adjusted for (age, sex, type of wards, comorbidities, liver and renal diseases), and the results were presented as odds ratios (ORs) with $95 \%$ confidence intervals (CIs). The reported $p$ values are two-tailed, and an $\alpha$ level of 0.05 was used to assess statistical significance. SPSS version 20 was used for data entry and analysis.

\section{Results}

During the study period, 160 patients admitted to the selected wards of YGH and YSH gave informed consent to be monitored for potential adverse effects up to 28 days after admission. Almost one-half (77 [48.1\%]) were admitted to the medical ward, 59 (36.9\%) to the surgical ward, and 24 (15.0\%) to the rheumatology ward.

A total of 65 ADRs were identified in 47 patients; $29.4 \%$ of patients admitted to these selected wards presented at least one suspected ADR. In 16 of these patients (one ADR each), the adverse effect was what led to admission; the remaining 49 ADRs appeared in 31 patients during their hospital stay (48 ADRs) or after discharge and before day 28 (one ADR). Table 1 shows the characteristics of all the recruited patients and the subsample of patients presenting one or more ADRs. The mean age of recruited patients was $46.7 \pm 17.2$ years; patients who presented an ADR were younger than those who did not. The initial sample of patients included 93 women $(58.1 \%)$ and 67 men (41.9\%), and a significantly higher proportion of women presented an ADR. Patients presenting an ADR took significantly more medications $(12.15 \pm 6.12)$ than those without ADRs $(7.99 \pm 4.15)$. No differences were seen in incidence of comorbidities and liver disease between patients with and without ADRs, but a higher proportion of those presenting a suspected ADR had renal disease.

The distribution of patients with ADRs in the different wards was as follows: 19 in the medical unit $(24.7 \%$ of patients admitted to that ward), 17 in the rheumatology unit (70.8\% of the patients admitted to that ward), and 11 in the surgical unit (18.6\% of those admitted in that ward). The multivariate analysis showed statistically significant differences in the proportion of ADRs identified in the different wards, with the highest proportion in rheumatology (OR 0.214 [95\% CI 0.072-0.632]; $p<0.0001$ ) (see Table 2).

Up to 61 ADRs could be attributed to 28 different medicines and six herbal remedies, whereas the causal medicine could not be clearly identified in four ADRs because of the concomitant use of different medicines (Table 3). The therapeutic groups most associated with these ADRs were corticosteroids (16 [29.1\%]), nonsteroidal anti-inflammatory drugs (NSAIDs; 8 [14.4\%]); opioids (7 [12.7\%]); and antibacterials $(6[10.8 \%])$. Table 3 summarizes the six herbal remedies suspected to have caused six of the ADRs.

More than one-third of the suspected ADRs (23 [35.4\%]) involved the gastrointestinal system, 14 (21.5\%) were blood and electrolyte disturbances, ten (15.4\%) were liver disorders, and eight (12.3\%) were classified as 'general ADRs' according to the WHO-ART dictionary. The most frequent individual ADRs identified were increased transaminase levels in ten patients (four taking standard antimycobacterial drugs, three taking herbal remedies, two taking a combination of drugs, and one taking ranitidine). Nine patients presented nausea/vomiting (13.8\%) associated with diverse medicines, seven patients presented hypokalaemia (five of which were after receiving methylprednisolone), five were diagnosed with upper gastrointestinal bleeding, and two had perforated peptic ulcers (Table 4). 
All Patients admitted to one Surgical ward, one Medical ward of YGH and one Rheumatology ward of YSH at the first day of the study

$$
\mathrm{n}=161
$$

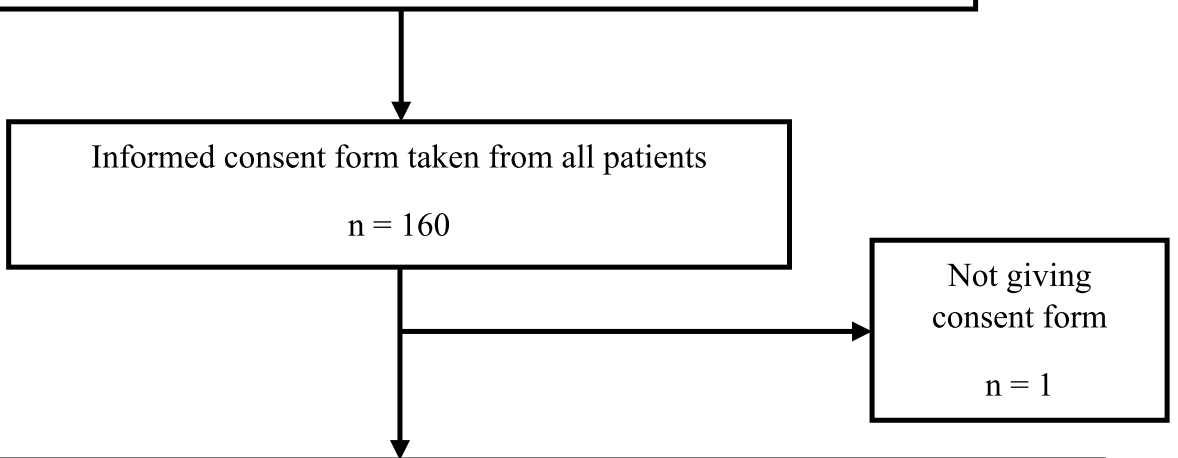

Suspected ADRs were screened and collected by face-to-face interview and reviewing clinical records including investigations on daily basis during 28 days

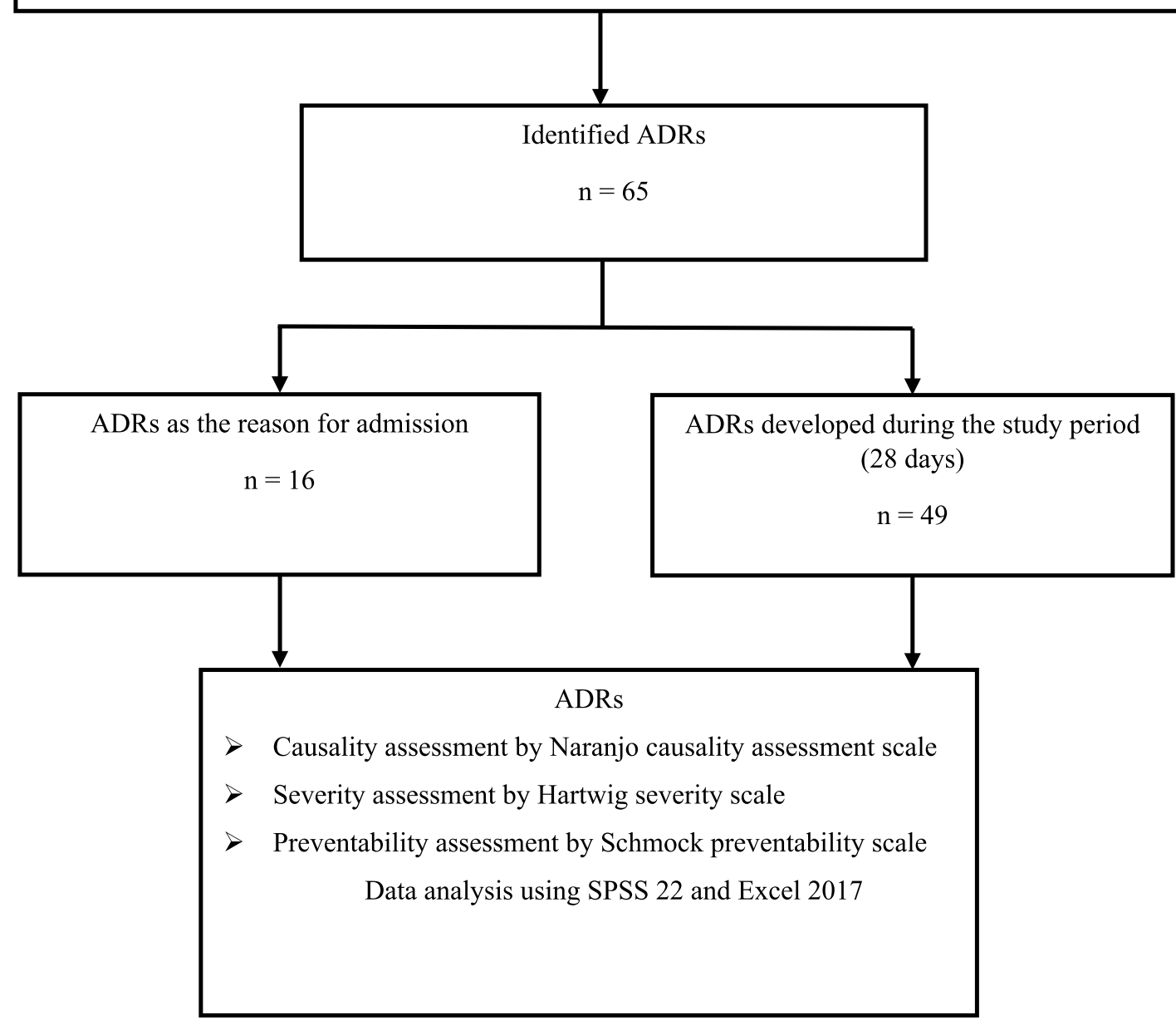

Fig. 1 Flowchart describing the patient selection and follow-up process (see Methods). ADR adverse drug reaction, $Y G H$ Yangon General Hospital, YSH Yangon Specialty Hospital

The most frequent ADRs-suspected drug combinations in the present study were low potassium levels in five patients receiving methylprednisolone, four patients with increased liver enzymes levels receiving antimycobacterial drugs, three patients with upper gastrointestinal bleeding receiving an NSAID or low-dose aspirin, three patients 
Table 1 Characteristics of patients admitted to the medical, surgical, and rheumatology units of the included hospitals presenting at least one $\operatorname{ADR}(n=47)$ and those not presenting ADRs $(n=113)$

\begin{tabular}{|c|c|c|c|c|c|}
\hline \multirow[t]{2}{*}{ Variable } & \multicolumn{3}{|l|}{ ADRs } & \multirow[t]{2}{*}{$t$ test } & \multirow{2}{*}{$\begin{array}{l}p \text { value (inde- } \\
\text { pendent sample } \\
t \text { test) }\end{array}$} \\
\hline & Present & Absent & Total & & \\
\hline Age (years) & $40.8 \pm 17.6$ & $49.2 \pm 16.5$ & $46.7 \pm 17.2$ & -2.862 & $0.005 *$ \\
\hline No. of medications & $12.15 \pm 6.12$ & $7.99 \pm 4.15$ & $9.21 \pm 5.16$ & 4.982 & $<0.001 *$ \\
\hline \multirow[t]{2}{*}{ Variable } & \multicolumn{3}{|l|}{ ADRs } & \multirow[t]{2}{*}{ OR $(95 \% \mathrm{CI})$} & \multirow[t]{2}{*}{$p$ (Chi-squared) } \\
\hline & Present & Absent & Total & & \\
\hline \multicolumn{6}{|l|}{ Age (years) } \\
\hline$<60$ & $37(32.5)$ & $77(67.5)$ & $114(100.0)$ & \multirow[t]{2}{*}{$1.730(0.775-3.861)$} & \multirow[t]{2}{*}{0.178} \\
\hline$\geq 60$ & $10(21.7)$ & $36(78.3)$ & $46(100.0)$ & & \\
\hline \multicolumn{6}{|l|}{ Sex } \\
\hline Male & $10(14.9)$ & $57(85.1)$ & $67(100.0)$ & \multirow[t]{2}{*}{$0.266(0.121-0.585)$} & \multirow[t]{2}{*}{$<0.001 * *$} \\
\hline Female & $37(39.8)$ & $56(60.2)$ & $93(100.0)$ & & \\
\hline \multicolumn{6}{|l|}{ Ward } \\
\hline Rheumatology & $17(70.8)$ & $7(29.2)$ & $24(100.0)$ & $0.135(0.049-0.375)$ & $<0.001 * *$ \\
\hline Surgical & $11(18.6)$ & $48(81.4)$ & $59(100.0)$ & \multirow[t]{2}{*}{$1.429(0.620-3.296)$} & \multirow[t]{2}{*}{0.402} \\
\hline Medical & $19(24.7)$ & $58(73.5)$ & $77(100.0)$ & & \\
\hline \multicolumn{6}{|l|}{ Comorbidity } \\
\hline Present & $20(27.8)$ & $52(72.2)$ & $72(100.0)$ & \multirow[t]{2}{*}{$0.869(0.437-1.726)$} & \multirow[t]{2}{*}{0.688} \\
\hline Absent & $27(30.7)$ & $61(69.3)$ & $88(100.0)$ & & \\
\hline \multicolumn{6}{|l|}{ Liver disease } \\
\hline Present & $2(14.3)$ & $12(85.7)$ & $14(100.0)$ & \multirow[t]{2}{*}{$0.374(0.080-1.741)$} & \multirow[t]{2}{*}{0.194} \\
\hline Absent & $45(30.8)$ & $101(69.2)$ & $146(100.0)$ & & \\
\hline \multicolumn{6}{|l|}{ Renal disease } \\
\hline Present & $9(56.3)$ & $7(43.8)$ & $16(100.0)$ & \multirow[t]{2}{*}{$3.586(1.249-10.300)$} & \multirow[t]{2}{*}{$0.013 * *$} \\
\hline Absent & $38(26.4)$ & $106(73.6)$ & $144(100.0)$ & & \\
\hline
\end{tabular}

Data are presented as mean \pm standard deviation or $N(\%)$ unless otherwise indicated

$A D R$ adverse drug reaction, $C I$ confidence interval, $O R$ odds ratio, $S D$ standard deviation

*Independent sample $t$ test, $p<0.001$

**Binary logistic regression, $p<0.05$

Table 2 Adjusted odds ratio for a multiple logistic regression model taking into account the presence or absence of adverse drug reactions, the wards where patients had been admitted, and the total number of medications received

\begin{tabular}{|c|c|c|c|c|}
\hline \multirow[t]{2}{*}{ Variable } & \multicolumn{2}{|l|}{ ADR } & \multirow[t]{2}{*}{ Adjusted OR (95\% CI) } & \multirow[t]{2}{*}{$p$ value } \\
\hline & Present & Absent & & \\
\hline \multicolumn{5}{|l|}{ Wards } \\
\hline Rheumatology & $17(70.8)$ & $7(29.2)$ & $0.214(0.072-0.632)$ & 0.005 \\
\hline Surgical & $11(18.6)$ & $48(81.4)$ & $1.111(0.463-2.664)$ & 0.814 \\
\hline Medical & $19(24.7)$ & $58(73.5)$ & & \\
\hline Medications $(n)$ & $12.15 \pm 6.12$ & $7.99 \pm 4.15$ & $0.888(0.817-0.965)$ & 0.005 \\
\hline
\end{tabular}

The model correctly classifies $76.9 \%$ of cases. The Chi-squared value associated with the Hosmer-Lemeshow (Chi-squared $=7.386, d f=8, p=0.496$ ) indicates a good overall model fit. Data are presented as mean \pm standard deviation or $N(\%)$ unless otherwise indicated

$A D R$ adverse drug reaction, $C I$ confidence interval, $O R$ odds ratio with constipation receiving tramadol, and three patients with increased transaminase levels receiving herbal remedies. These five pairs of ADR-suspected drugs represented more than one-quarter of the 65 ADRs identified in this study.
Causality assessment of the 65 identified ADRs according to the Naranjo algorithm showed five 'definite' (7.7\%), 27 'probable' (41.5\%), and 33 (50.8\%) 'possible' associations. According to the Hartwig severity scale, 45 ADRs required 
Table 3 Classification of the suspected medicines involved in the 65 ADRs identified in the different wards of the included hospitals

\begin{tabular}{|c|c|c|}
\hline Medicines, therapeutic group & Active ingredient $(n)$ & ADRs \\
\hline Corticosteroids & $\begin{array}{l}\text { Methylprednisolone (12) } \\
\text { Prednisolone (4) }\end{array}$ & $16(29.1)$ \\
\hline NSAIDs & $\begin{array}{l}\text { Aspirin (80 mg) (2) } \\
\text { Diclofenac (2) } \\
\text { Other NSAIDs (4) }\end{array}$ & $8(14.4)$ \\
\hline Opioids & $\begin{array}{l}\text { Tramadol (4) } \\
\text { Codeine (1) } \\
\text { Nalbuphine (2) }\end{array}$ & $7(12.7)$ \\
\hline Antibacterial agents & $\begin{array}{l}\text { Levofloxacin (3) } \\
\text { Other (3) }\end{array}$ & $6(10.8)$ \\
\hline Antimycobacterial drugs & HRZE (4) & $4(7.3)$ \\
\hline Drugs used in rheumatology & $\begin{array}{l}\text { Cyclophosphamide (3) } \\
\text { Hydroxychloroquine (1) }\end{array}$ & $4(7.3)$ \\
\hline Cardiovascular drugs & $\begin{array}{l}\text { ACEIs and CCBs (2) } \\
\text { Isosorbide mononitrate (1) }\end{array}$ & $3(5.5)$ \\
\hline Blood disorders & $\begin{array}{l}\text { Warfarin (2) } \\
\text { Tranexamic acid (1) }\end{array}$ & $3(5.5)$ \\
\hline Other $^{\mathrm{a}}$ & & $4(7.3)$ \\
\hline Total patients with ADRs caused by drugs & & $55(100)$ \\
\hline ADRs in patients receiving more than one drug ${ }^{\mathrm{b}}$ & & 4 \\
\hline ADRs in patients taking herbal remedies & & \\
\hline Pan Wut Hmone (increased transaminase) & & 1 \\
\hline Myat Thu Kha (increased transaminase) & & 1 \\
\hline Tha Hmar Ni (increased transaminase) & & 1 \\
\hline Chan Saint (haematemesis and melena) & & 1 \\
\hline Kyar Pyan (haematemesis and melena) & & 1 \\
\hline Unknown (congestive heart failure) & & 1 \\
\hline Total ADRs in patients taking herbal remedies & & 6 \\
\hline
\end{tabular}

ADRs are presented as $n(\%) .55$ ADRs were attributed to single drugs, four ADRs were diagnosed in patients receiving more than one medicine and the causal medicine could not be clearly identified; six ADRs were attributed to herbal remedies

$A C E I s$ angiotensin-converting enzyme inhibitors, $A D R$ adverse drug reaction, $C C B s$ calcium channel blockers, HRZE isoniazid + rifampicin + pyrazinamide + ethambutol, NSAID nonsteroidal anti-inflammatory drug

${ }^{a}$ One patient each: insulin, mesna, ranitidine, potassium chloride

${ }^{\mathrm{b}}$ The four ADRs diagnosed in patients treated with more than one medicine, and the causal one could not be identified: (1) a combination of frusemide and methylprednisolone was associated with hypokalaemia; (2) levofloxacin, perindopril, and statin associated with increased transaminase levels; (3) sulbactam, cefoperazone, metronidazole, and azithromycin associated with gastrointestinal disturbance; and (4) valproate and leflunomide associated with increased transaminase levels some action (69.2\%) and 20 required no change in treatment $(30.8 \%)$. Among the 45 ADRs requiring some action, 20 received another treatment $(44.4 \%) ; 16(35.5 \%)$ led to hospital admission; six $(13.3 \%)$ required treatment with the suspected drug to be held, discontinued, or otherwise changed; and three $(6.7 \%)$ prolonged the hospital stay.

Analysis with the Schumock preventability scale identified the ADRs that could have been avoided. More than onehalf of the ADRs either definitely or probably could have been prevented (25 [38.5\%] and 10 [15.4\%], respectively).
A few of these preventable ADRs were potentially severe: at least five cases of hypokalaemia associated with methylprednisolone, three cases of gastrointestinal bleeding associated with NSAIDs, three cases of increased transaminase levels, and two of gastrointestinal bleeding after taking a traditional medicine.

As noted, admission of 16 of these 160 patients was prompted by an ADR (10\% of the study sample): six cases of increased liver enzymes (four caused by HRZE [isoniazid + rifampicin + pyrazinamide + ethambutol] and two 
Table 4 Association between ADR and suspected medicine in the 65 ADRs observed in this study

\begin{tabular}{|c|c|c|c|c|}
\hline Organ/system & $N(\%)$ & Suspected ADRs & $n$ & Associated drugs $(n)$ \\
\hline \multirow[t]{7}{*}{ Digestive } & $23(35.4)$ & Nausea/vomiting & 9 & $\begin{array}{l}\text { Levofloxacin (2) } \\
\text { Cyclophosphamide (2) } \\
\text { Codeine (1) } \\
\text { Ketorolac (1) } \\
\text { Nalbuphine (1) } \\
\text { Tramadol (1) } \\
\text { Combined medicines }^{\mathrm{a}}(1)\end{array}$ \\
\hline & & Constipation & 4 & $\begin{array}{l}\text { Tramadol (3) } \\
\text { Diclofenac (1) }\end{array}$ \\
\hline & & Upper gastrointestinal bleeding & 5 & $\begin{array}{l}\text { NSAID (2) } \\
\text { Herbal remedy (2) } \\
\text { ASA }(80 \mathrm{mg})(1)\end{array}$ \\
\hline & & Peptic ulcer perforation & 2 & NSAIDs (2) \\
\hline & & Gastritis & 1 & Prednisolone (1) \\
\hline & & Loss of appetite & 1 & Cyclophosphamide (1) \\
\hline & & Loose stools & 1 & Piperacillin (1) \\
\hline \multirow[t]{6}{*}{ Blood } & $14(21.5)$ & Hypokalaemia & 7 & $\begin{array}{l}\text { Methylprednisolone (5) } \\
\text { Insulin (1) } \\
\text { Combined medicines }^{\mathrm{a}}(1)\end{array}$ \\
\hline & & Increased INR & 2 & Warfarin (2) \\
\hline & & Bruise & 2 & $\begin{array}{l}\text { Aspirin (1) } \\
\text { Methylprednisolone (1) }\end{array}$ \\
\hline & & Hyperglycaemia & 1 & Methylprednisolone (1) \\
\hline & & Hyperkalaemia & 1 & Potassium chloride (1) \\
\hline & & Leucocytosis & 1 & Prednisolone (1) \\
\hline Liver & $10(15.4)$ & Increased transaminase level & 10 & $\begin{array}{l}\text { HRZE (4) } \\
\text { Herbal remedy (3) } \\
\text { Combined medicines }^{\mathrm{a}}(2) \\
\text { Ranitidine (1) }\end{array}$ \\
\hline \multirow[t]{4}{*}{ General } & $8(12.3)$ & $\begin{array}{l}\text { Chill } \\
\text { Dizziness }\end{array}$ & $\begin{array}{l}1 \\
3\end{array}$ & $\begin{array}{l}\text { Mesna (1) } \\
\text { Nalbuphine (1) } \\
\text { Cilnidipine (1) } \\
\text { Metronidazole (1) }\end{array}$ \\
\hline & & Headache & 2 & $\begin{array}{l}\text { Cefepime (1) } \\
\text { Isosorbide mononitrate (1) }\end{array}$ \\
\hline & & Proximal myopathy & 1 & Prednisolone (1) \\
\hline & & Sore throat & 1 & Methylprednisolone (1) \\
\hline Respiratory & $4(6.2)$ & $\begin{array}{l}\text { Dry cough } \\
\text { Chest infection }\end{array}$ & $\begin{array}{l}1 \\
3\end{array}$ & $\begin{array}{l}\text { Enalapril (1) } \\
\text { Prednisolone (1) } \\
\text { Methylprednisolone (2) }\end{array}$ \\
\hline \multirow[t]{2}{*}{ Skin } & $3(4.6)$ & Itchiness (2) & 2 & $\begin{array}{l}\text { Levofloxacin (1) } \\
\text { Tranexamic acid (1) }\end{array}$ \\
\hline & & Poor wound healing (1) & 1 & Methylprednisolone (1) \\
\hline Eyes & $2(3.1)$ & $\begin{array}{l}\text { Blurred vision } \\
\text { Glaucoma }\end{array}$ & $\begin{array}{l}1 \\
1\end{array}$ & $\begin{array}{l}\text { Hydroxychloroquine (1) } \\
\text { Steroid (1) }\end{array}$ \\
\hline Cardiovascular & $1(1.5)$ & Congestive heart failure & 1 & Herbal remedy (1) \\
\hline
\end{tabular}

Each patient can present more than one ADR; one medicine can produce more than one ADR

$A D R$ adverse drug reaction, $A S A$ acetylsalicylic acid, $H R Z E$ isoniazid, rifampicin, pyrazinamide, ethambutol, INR international normalised ratio, NSAIDs nonsteroidal anti-inflammatory drugs

${ }^{a}$ Combined medicines: (1) a combination of frusemide and methylprednisolone was associated with hypokalaemia; (2) levofloxacin, perindopril, and statin was associated with increased transaminase levels; (3) sulbactam, cefoperazone, metronidazole, and azithromycin were associated with gastrointestinal disturbances, and (4) valproate and leflunomide were associated with increased transaminase levels 
attributed to herbal remedies), five gastrointestinal bleeding (two attributed to NSAIDs, two to herbal remedies, and one to low-dose aspirin), two gastric ulcer perforations associated with NSAIDs, one heart failure attributed to a traditional medicine, one hyperglycaemia due to methylprednisolone, and one prednisolone-induced chest infection.

\section{Discussion}

The present active pharmacovigilance study conducted in two hospitals in Yangon, Myanmar, showed that, in the selected wards, $29.4 \%$ of the admitted patients were diagnosed as having at least one ADR, either prompting the admission (16 patients [10\%]) or complicating their hospitalisation (31 patients [19\%]). A systematic review and meta-analysis published in 2017 showed a wide range of ADR prevalence in inpatients in Western countries, ranging from 3.9 to $57.9 \%$ in 12 studies [12]. A 3-month study conducted in Singapore General Hospital, a 1600-bed tertiary teaching hospital, reported the prevalence of all ADRs at admission to be $12.4 \%$ (95\% CI 10.5-14.6) and of ADRs causing admission to be $8.1 \%$ (95\% CI 6.5-10.0); the most common ADRs were related to the gastrointestinal system, and cardiovascular drugs were the most frequently involved drugs [13]

Two-thirds of the ADRs in the current study required some action from health professionals to be stopped or cured, thus suggesting that awareness of the adverse effects of drugs and potentiating of pharmacovigilance in hospitals is important to improve not only quality of care but also patient safety. Last, but not least, according to the Schumock preventability scale, more than one-half of these ADRs could have been avoided, another reason to consider these results as a starting point to raise awareness of the important role of hospital pharmacovigilance, one of the cornerstones of a national pharmacovigilance programme.

ADRs can be undiagnosed unless a health professional specifically asks about them. If not identified as an ADR, these symptoms easily become candidates for cascade treatments, which lead to polypharmacy, potential drug-drug interactions, and additional ADRs [14]. Since ADRs sometimes hide behind common presenting symptoms and occasionally present bizarrely, a good anamnesis will help identify these hidden ADRs. In both situations, knowledge of pharmacovigilance, the pharmacovigilance system, and how to report suspected ADRs is important [15].

The present study showed that one surgical ward, one medical ward, and one speciality ward are suitable places to study the prevalence of ADRs because almost all hospitals in our country contain surgical and medical wards, so both wards can represent most hospitals. One speciality ward was added to explore the prevalence of suspected ADRs in such a ward.

Our findings indicated that $29.4 \%$ of patients were either admitted because of an ADR or developed an ADR during hospitalisation. The prevalence of ADRs in the present study was high, but it should be remembered that researchers performed an active search for ADRs and that the reporting system is not well practised in Myanmar. Therefore, data on the incidence of ADRs are also scant. A study conducted in eight tertiary care teaching hospitals in Yangon showed that $48.1 \%$ of the postgraduate students (who were training to become specialist clinicians) had never heard of ADRs, 91.4\% had not seen the Myanmar ADR reporting form, and $82.8 \%$ did not know which department an ADR should be reported to [6]. Therefore, the main barriers to ADR reporting seem to be related to the awareness of ADRs, as has been described in other countries [15].

Three ADR-suspect drug pairs accounted for almost onequarter of the identified ADRs, found in one-third of the patients included in the study sample. These cases and a few other identified ADRs were well-known and, according to the Schumock and Thornton scale [11], potentially avoidable. These findings agree with those of other larger studies conducted in other countries, which also described a concentration of ADRs in a few well-known unwanted effects produced by some common medicines [3]. Prevention in pharmacovigilance is very important to increase patient safety and the quality of healthcare.

\section{Conclusions}

The present study was conducted in two tertiary care university hospitals of Yangon during the first quarter of 2019. Therefore, the figures obtained cannot be extrapolated to other hospitals or even to the rest of the country. Notwithstanding this limitation, the suspected ADRs actually happened. Therefore, the study achieved the main objective of providing evidence to participating hospitals that ADRs do occur, a first step to increasing awareness of drug safety and strengthening pharmacovigilance in Myanmar.

Acknowledgements The authors thank Professor Dr. Zaw Than Htun, Professor Dr. Zaw Wai Soe, Dr. Theingyi Zin, Dr. Valerio Reggi, and Dr. Susann Roth. We also thank Dr. Lei Htay and our colleagues at the Department of Pharmacology, University of Medicine 1, Yangon, Department of Rheumatology, 500-bed Yangon Specialty Hospital, Department of Medicine and Department of Surgery, Yangon General Hospital, for their kind help, advice, and support.

\section{Compliance with Ethical Standards}

Conflict of interest Lwin Moe May, Albert Figueras, Ye Htut Linn, Maw Than Htike, Mi Kun Kaw San, Nyein Chan Pyae, Khin Hnin Aye, Ei Ei Aung, Nilar Win, Wine Thawda, Zin Wah Linn, Yin Min Kyaw, 
Ya Min, Zaw Win Than, Moe Pan Khaing, Thurein Win, Pyi Phyo $\mathrm{Htet}, \mathrm{Nu} \mathrm{Nu}$ Aye have no conflicts of interest that are directly relevant to the content of this article.

Funding This research was funded by the Department of Medical Research External Grant 2019 (ID: 12/2019) of the Ministry of Health and Sports, Republic of the Union of Myanmar. Training and consultancy activities by Albert Figueras were partly supported by the Asian Development Bank (TA-8763 REG: Drug Safety Expert)—(replacement of regulatory specialist/contract no. 120958-S85781).

Ethical Approval The Ethics Review Committee, Department of Medical Research, Ministry of Health and Sports, Republic of the Union of Myanmar, approved this study (approval number: Ethics/DMR/2018/131). All procedures performed in this study were in accordance with the ethical standards of the institutional and/or national research committee and with the 1964 Helsinki declaration and its later amendments or comparable ethical standards. Written informed consent was obtained from all individual participants included in the study.

Open Access This article is licensed under a Creative Commons Attribution-NonCommercial 4.0 International License, which permits any non-commercial use, sharing, adaptation, distribution and reproduction in any medium or format, as long as you give appropriate credit to the original author(s) and the source, provide a link to the Creative Commons licence, and indicate if changes were made. The images or other third party material in this article are included in the article's Creative Commons licence, unless indicated otherwise in a credit line to the material. If material is not included in the article's Creative Commons licence and your intended use is not permitted by statutory regulation or exceeds the permitted use, you will need to obtain permission directly from the copyright holder.To view a copy of this licence, visit http://creativecommons.org/licenses/by-nc/4.0/.

\section{References}

1. Lazarou J, Pomeranz B, Corey PN. Incidence of adverse drug reactions in hospitalized patients: a meta-analysis of prospective studies. JAMA. 1998;279:1200-5.

2. European Commission. Commission staff working document. Pharmacovigilance related activities of Member States and the European Medicines Agency concerning medicinal products for human use (2012-2014). https://ec.europa.eu/health//sites/healt h/files/files/pharmacovigilance/pharmacovigilance-report-20122014_annex_en.pdf. Accessed 23 Oct 2019.

3. Budnitz DS, Lovegrove MC, Shehab N, Richards CL. Emergency hospitalizations for adverse drug events in older Americans. N Engl J Med. 2011;365:2002-12. https://doi.org/10.1056/NEJMs a1103053.
4. WHO. The Importance of Pharmacovigilance. http://apps.who. int/medicinedocs/pdf/s4893e/s4893e.pdf?ua=1. Accessed 23 Oct 2019.

5. Uppsala Monitoring Center. Members of WHO Programme for International Drug Monitoring. Uppsala Reports 2019;80:4-5. https://view.publitas.com/uppsala-monitoring-centre/uppsalareports-80/page/1. Accessed 23 Oct 2019.

6. Aye-Pwint-Phyu, Waing-Thawdar, Ye-Htut-Linn Kay-Khine-Thu, Thida-Tun, Lwin-Moe-May. Myat Myat Soe and Nu-Nu-Aye (2018). Barriers to Implementing Adverse Drug Reaction Reporting System. Technical Report of Department of Pharmacology, University of Medicine 1, Yangon (Thesis), 2018.

7. Thura-Kyaw. Knowledge, attitude and practice of adverse drug reaction reporting system among the assistant surgeons in teaching hospitals. M.Med.Sc (Pharmacology), University of Medicine 2, Yangon (Thesis), 2017.

8. Nang-Khan-Li. Active monitoring of adverse drug reactions on fixed dose combinations of anti-tuberculous drugs. M.Med.Sc (Pharmacology), University of Medicine 2, Yangon (Thesis), 2017.

9. Naranjo CA, Busto U, Sellers EM, Sandor P, Ruiz I, Roberts EA, Janecek E, Domecq C, Greenblatt DJ. A method for estimating the probability of adverse drug reactions. Clin Pharmacol Ther. 1981;30:239-45.

10. Hartwig SC, Siegel J, Schneider PJ. Preventability and severity assessment in reporting adverse drug reactions. Am J Hosp Pharm. 1992;49:2229-32.

11. Raut AL, Patei P, Patel C, Pawar A. Preventability, predictability and seriousness of adverse drug reactions amongst medicine inpatients in a teaching hospital: a prospective observational study. Int J Pharm Chem Sci. 2012;1:1293-9.

12. Laatikainen $\mathrm{O}$, Miettunen J, Lehtiniemi H, Tenhunen O. The prevalence of medication-related adverse events in inpatientsa systemic review and meta-analysis. Eur J Clin Parmacol. 2017;73:1539-49.

13. Chan SL, Ang X, Levana L, Sani LL, Ng HY, Winther MD, Liu JJ, Brunham LLR, Chan A. Prevalence and characteristics of adverse drug reactions at admission to hospital: a prospective observational study. Br J Clin Pharmacol. 2016;82:1636-46.

14. McCarthy LM, Visentin JD, Rochon PA. Assessing the scope and appropriateness of prescribing cascades. J Am Geriatr Soc. 2019;67:1023-6. https://doi.org/10.1111/jgs. 15800.

15. Pérez M, Figueras A. The lack of knowledge about the voluntary reporting system of adverse drug reactions as a major cause of underreporting: direct survey among health professionals. Pharmacoepidemol Drug Saf. 2011;20:1295-302. 